Full length article

\title{
The Mediterranean European hake, Merluccius merluccius: Detecting drivers influencing the Anisakis spp. larvae distribution
}

\author{
Paolo Cipriani $^{\mathrm{a}, \mathrm{b}, *}$, Gian Luca Sbaraglia ${ }^{\mathrm{b}}$, Michela Paoletti ${ }^{\mathrm{b}}$, Lucilla Giulietti ${ }^{\mathrm{b}}$, Bruno Bellisario ${ }^{\mathrm{b}}$, \\ Marialetizia Palomba $^{\mathrm{b}}$, Ivana Bušelićc ${ }^{\mathrm{c}}$, Ivona Mladineo ${ }^{\mathrm{c}}$, Giuseppe Nascetti ${ }^{\mathrm{b}}$, \\ Simonetta Mattiucci ${ }^{\mathrm{a}, *}$
}

\footnotetext{
a Department of Public Health and Infectious Diseases, Section of Parasitology, "Sapienza-University of Rome", P.le Aldo Moro, 5, 00185 Rome, Italy

b Department of Ecological and Biological Sciences (DEB) Tuscia University, Viterbo, Italy

${ }^{c}$ Laboratory for Aquaculture, Institute of Oceanography and Fisheries, Split, Croatia
}

\section{A R T I C L E I N F O}

\section{Keywords:}

Mediterranean sea

Anisakis pegreffii

Anisakis physeteris

Fishing grounds

Epidemiology

\begin{abstract}
A B S T R A C T
The European hake Merluccius merluccius is one of the most commercially important and widely distributed fish species, occurring both in European and Mediterranean Sea fisheries. We analyzed the distribution and infection rates of different species of Anisakis in $M$. merluccius ( $\mathrm{N}=1130$ hakes), by site of infection in the fish host (viscera, dorsal and ventral fillets) from 13 different fishing grounds of the Mediterranean Sea (FAO area 37). The fillets were examined using the UV-Press method. A large number of Anisakis specimens $(\mathrm{N}=877)$ were identified by diagnostic allozymes, sequence analysis of the partial EF1 $\alpha$-1 region of nDNA and mtDNA cox2 gene. Among these, 813 larvae corresponded to A. pegreffii, 62 to A. physeteris, 1 to A. simplex (s. s.), whereas one resulted as a F1 hybrid between $A$. pegreffii and $A$. simplex (s. s.). Remarkably high levels of infection with $A$. pegreffii were recorded in hakes from the Adriatic/Ionian Sea compared to the fish of similar length obtained from the western Mediterranean fishing grounds. A positive correlation between fish length and abundance of $A$. pegreffii was observed. Concerning the localization of $A$. pegreffii larvae in the fish, $28.3 \%$ were detected in the liver, $62.9 \%$ in the rest of the viscera, $6.6 \%$ in the ventral part of the flesh, whereas $2.1 \%$ in the dorsal flesh.
\end{abstract}

\section{Introduction}

The European hake Merluccius merluccius (L., 1758) is one of the most economically important fish species, occurring both in North-East Atlantic (Casey and Pereiro, 1995) and Mediterranean Sea fisheries (Oliver and Massutí, 1995; Ardizzone and Corsi, 1997; Abaunza et al., 2001). The existence of different intra-specific stocks in European waters has been suggested on the basis of a multi-method approach (Inada, 1981; Alheit and Pitcher, 1995; Roldan et al., 1998; Lundy et al., 1999; Mattiucci et al., 2014a). In fact, north-east Atlantic and Mediterranean Sea populations have been considered as genetically separated stocks (Abaunza et al., 2001; Cimmaruta et al., 2005; Milano et al., 2014). The Atlantic and Mediterranean hake populations exhibit remarkable differences in demographic and life history traits, such as growth rate, size at maturity, recruitment patterns and spawning season (Froese and Pauly, 2013). The species is caught commercially throughout its range. It has a high price in Europe, being mainly sold fresh in both Italian and Spanish markets, and represents one of the most valuable and heavily exploited demersal species in the western European fisheries (Casey and
Pereiro, 1995).

The genus Anisakis includes species of heteroxenous parasites of marine organisms, with crustaceans as first intermediate hosts, fishes and squids as intermediate and/or paratenic hosts, and mainly cetaceans as definitive hosts (Mattiucci and Nascetti, 2006, 2008). The larval stages of Anisakis spp. commonly infect the viscera and musculature of many teleost species (Mattiucci and Nascetti, 2008; Mattiucci et al., 2017a). Nine species of Anisakis have been detected and genetically characterized (Mattiucci et al., 2009; 2014b). Their third larval stage, recovered from fish hosts and invertebrates, exhibits morphotypes indicated as Anisakis Type I or Type II (sensu Berland, 1961), but they cannot be identified at the species level based on conventional morphological analysis. Among the genetic methodologies used for the species identification of Anisakis larvae, allozyme markers represent a valuable tool. Allozymes markers are based on several diagnostic loci, that being fixed for alternative alleles among those highly polymorphic loci studied in distinct species of Anisakis (see Mattiucci et al., 2009), permit to recognize the species at any life-history stages. In addition, a new nuclear marker based on the sequences analysis of the EF1 $\alpha-1$

\footnotetext{
* Corresponding authors at: Department of Public Health and Infectious Diseases, Section of Parasitology, "Sapienza-University of Rome", P.le Aldo Moro, 5, 00185 Rome, Italy.

E-mail addresses: paolocipr@gmail.com (P. Cipriani), simonetta.mattiucci@uniroma1.it (S. Mattiucci).
} 
nDNA locus has been found. It allows the correct identification of the two species A. simplex (s. s.) and A. pegreffii, due to fixed alternative nucleotide positions in the two species (Mattiucci et al., 2016). Further, the mtDNA $\operatorname{cox} 2$ revealed fixed alternative nucleotide differences in distinct species of the genus Anisakis, which allows their correct identification (Valentini et al., 2006). The combined use of those different markers permits a multilocus genotyping approach in the identification process of Anisakis spp. specimens (Mattiucci et al., 2014b, 2016).

Previous genetic/molecular identification of Anisakis spp. larvae occurring in the European hake $M$. merluccius sampled in the Mediterranean Sea revealed that $A$. pegreffii and A. physeteris are the most common species, whereas A. simplex (s. s.) and A. typica were recovered, respectively, only in Southern areas or nearby Gibraltar Strait and the Alboran Sea (Mattiucci et al., 2004; Valero et al., 2006; Farjallah et al., 2008). In addition, statistically significant differences observed in the distribution patterns of genetically identified Anisakis spp. larvae from hakes caught in different fishing grounds, have also been used as biomarkers in the stock characterization of fish species in European waters (Mattiucci et al., 2004, 2014a). However, no detailed information was available regarding the levels of infection with different species of Anisakis by location in the fish host (i.e. viscera and flesh of hake) and from different fishing grounds of the Mediterranean Sea. Indeed, in addition to the ecological aspects related to the differential distribution of Anisakis spp. from this fish host, data on their distribution in the edible parts of the fish for humans, as compared with the viscera, are important, since larval Anisakis are etiological agents of human anisakiasis. Over the last 30 years, there has been an increase in cases of human anisakiasis throughout the world (Bao et al., 2017; Mattiucci et al., 2017a). So far, among the nine species of Anisakis genetically characterized (Mattiucci and Nascetti, 2008; Mattiucci et al., 2009), A. simplex (s. s.) and A. pegreffii are currently reported as zoonotic species causing human anisakiasis (D'Amelio et al., 1999; Umehara et al., 2007; Fumarola et al., 2009; Mattiucci et al., 2011, 2013, 2017b; Arai et al., 2014; Lim et al., 2015; Mladineo et al., 2016). In addition to the consumer health implications, anisakid nematodes also impact fish quality in terms of aesthetics, due to their repellent appearance when they occur in fish intended for human consumption (Karl and Levsen, 2011; Levsen and Karl, 2014).

The aim of the present study was to detect the major drivers influencing the distribution with Anisakis spp. larvae in Merluccius merluccius from the Mediterranean Sea. We studied the infection with of Anisakis species in the viscera and flesh of European hakes, caught in different fishing grounds of the Mediterranean Sea in order to: i) identify Anisakis larvae at species level using multilocus genotyping approach, ii) provide parasite epidemiological data by fish size and fishing grounds for future development of risk assessment models of anisakiasis in the Mediterranean Sea.

\section{Materials and methods}

\subsection{Fish sampling}

A total of 1130 specimens of European hake Merluccius merluccius were obtained from 13 different fishing grounds of the Mediterranean Sea (Fig. 1 Table 1), between June 2013 and June 2016 (Table 1) in the framework of the PARASITE Project. The fish were collected in the early morning at fish landings, immediately frozen and shipped by a refrigerated truck to the laboratories of the Parasitology Section at the Department of Public Health and Infection Diseases of "Sapienza-University" of Rome, and the Laboratory for Aquaculture of the Institute of Oceanography and Fisheries in Split, Croatia. The fish were kept frozen at $-20{ }^{\circ} \mathrm{C}$ until the parasitological examination. The temperature of storage was monitored during the transport using a data logger, and it was kept constant below $0{ }^{\circ} \mathrm{C}$ for the refrigerated samples, taking into account that a post-mortem migration of the Anisakis spp. larvae present could occur in the fish flesh when storage temperature is above $2{ }^{\circ} \mathrm{C}$
(Cipriani et al., 2016).

\subsection{Parasitological analysis}

All the specimens were measured (total length) to the nearest $0.1 \mathrm{~cm}$ and weighted before being processed for the parasitological examination. The mean length and weight are reported in Table 1. Fulton's condition factor $\left(\mathrm{K}=\mathrm{W}(\mathrm{g}) * 10^{5} / \mathrm{L}^{3}(\mathrm{~mm})\right.$ ) was calculated for hakes of each sampling area.

The hakes were gutted, and the viscera of each individual was separated. Flesh was cut into two to four portions of fillets, separating the hypaxial (ventral) and epaxial (dorsal) regions, following the horizontal septum, and afterwards it was placed in individual plastic bags, pressed under hydraulic press and stored overnight at $-20{ }^{\circ} \mathrm{C}$ for subsequent detection of larvae under UV light (Karl and Leinemann, 1993; Karl and Levsen, 2011; Levsen et al., in press). The larvae were counted and identified to genus level using an optical microscope according to the diagnostic morphological keys (sensu Berland, 1961). Anisakis spp. Types I and II, and Hysterothylacium spp. larvae were washed in saline solution and stored in Eppendorf tubes at $-70^{\circ} \mathrm{C}$ until their further genetic identification.

All the data for the fish (sampling area, date of catch, length, weight) and nematodes (number, localization in the fish host, identification) was collected and reported in a Biobanking platform specifically designed within the PARASITE project (González et al., 2017).

\subsection{Genetic identification of larval nematodes}

A subsample of 877 Anisakis spp. larvae (out of the total 28783 collected), corresponding to $3 \%$ of the larvae recovered in all the fish specimens from different fishing grounds, were identified to the species level by a multi-marker genotyping approach. Each specimen of Anisakis was cut in two parts; one part was used for three diagnostic allozymes loci (Mattiucci et al., 2009), whereas the other part was stored in 96\% ethyl alcohol until DNA extraction. The total DNA was extracted using the Quick-gDNA MiniPrep (column format) by Zymo Research from $2 \mathrm{mg}$ of homogenized tissues from each specimen, following the manufacturer's protocol (Levsen et al., in press).

The diagnostic allozyme loci (Adk-2, Pep C-1 and Pep C-2) were analyzed according to established procedures (see Mattiucci et al., 2009, 2014b) on 877 Anisakis spp. larvae. In addition, a subsample of 240 larvae randomly selected among those identified by allozymes were studied by direct sequence analysis of mitochondrial (mtDNA cox2, $629 \mathrm{bp}$ ) (Mattiucci et al., 2014b) and nuclear (elongation factor EF1 $\alpha-1$ of nDNA, 409 bp) genes (Mattiucci et al., 2016).

The mitochondrial cytochrome C oxidase subunit II (cox2) gene was amplified using the primers $211 \mathrm{~F}$ (5'TTTTCTAGTTATATAGATTGRTTYAT-3') and 210R (5'CACCAACTCTTAAAATTA TC-3') (Valentini et al., 2006; Mattiucci et al., 2014b). Polymerase chain reaction (PCR) was carried out according to the previously described procedures (Mattiucci et al., 2014b). The sequences obtained at the mtDNA $\operatorname{cox} 2$ for the larval nematodes were compared with those already obtained for the same gene and deposited in GenBank: A. simplex (s. s.) (DQ116426), A. pegreffii (JQ900761), A. berlandi (KC809999), A. typica (DQ116427), A. ziphidarum (DQ116430), A. nascettii (FJ685642), A. physeteris (DQ116432), A. brevispiculata (DQ116433) and A. paggiae (DQ116434).

The elongation factor (EF1 $\alpha-1$ nDNA) nuclear gene was amplified using the primers EF-F (5'-TCCTCAAGCGTTGTTATCTGTT-3') and EF-R (5'-AGTTTTGCCACTAGCGGTTCC-3') (Mattiucci et al., 2016). The PCR conditions and procedures followed those reported in Mattiucci et al., 2016. The sequences obtained at the EF1 $\alpha-1$ gene of the nDNA for the larval specimens of $A$. pegreffii and A. simplex (s. s.) were compared at the diagnostic positions (i.e 186, and 286) as previously detailed (Mattiucci et al., 2016).

In addition, 16 larval specimens of Hysterothylacium spp. randomly 


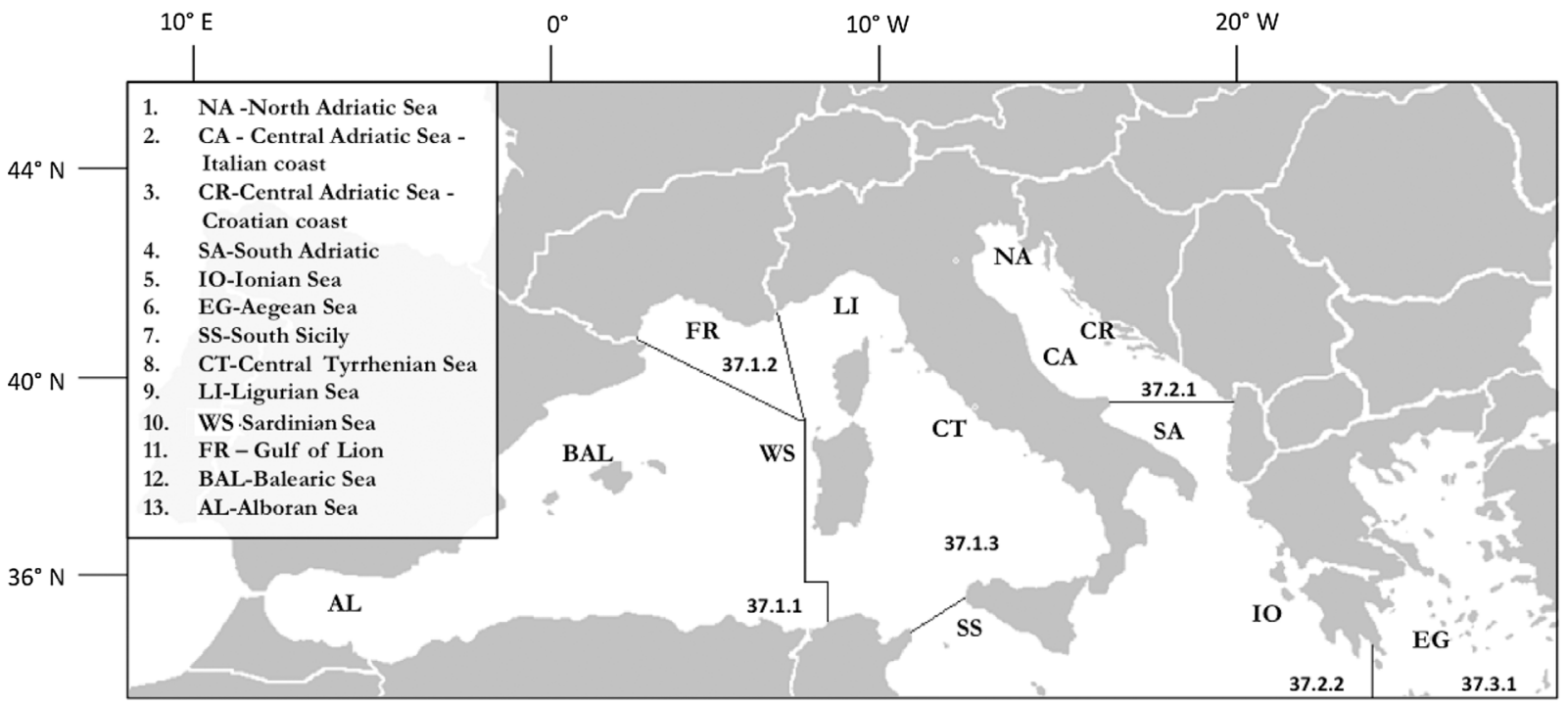

Fig. 1. Sampling localities (see Table 1) of specimens of Merluccius merluccius, examined in the present study.

selected from all the infected hakes sampled in the different Mediterranean fishing localities were identified to species level by sequence analysis of the internal transcribed spacers (ITS rDNA) region. The DNA was extracted using the same procedure reported above for Anisakis spp. PCR amplification was performed using the primers NC5 (5'-GTAGGTGAACCTGCGGAAGGATCATT-3') and NC2 (5'TTAGTTTCTTTTCCTCCGCT-3'), as reported in Zhu et al. (2000). PCR conditions were those described by Zhu et al. (2000). All the sequences obtained were analyzed by GenBank Blast software and aligned with previously characterized sequences of the Raphidascarididae, by ClustalX (Thompson et al., 1997).

A Bayesian inference (BI) tree, based on mtDNA cox2 gene sequences of $A$. pegreffii larvae from Merluccius merluccius sampled in the Mediterranean Sea, with respect to the other Anisakis spp. previously sequenced, was elaborated. The analysis was performed by MrBayes3.1
(Huelsenbeck and Ronquist, 2005) using TIM1 + I + G substitution model as implemented in jModeltest2.1 (Darriba et al., 2012). The parameters for the selected model were $\mathrm{I}=0.392$ and $\mathrm{G}=0.463$, calculated with Akaike Information Criterion (AIC) (Posada and Buckley, 2004). For the Bayesian analysis, four incrementally heated Markov Chains (using default heating values) were run for 1,000,000 generations, sampling the Markov Chains at intervals of 100 generations. Numbers at the nodes are posterior probabilities; Toxocara canis and Pseudoterranova ceticola were used as outgroups.

\subsection{Statistical analysis of the epidemiological data}

The levels of infection with Anisakis spp. larvae in the hakes were calculated for each sampling area. The epidemiological parameters considered were: prevalence $(\mathrm{P}, \%)$ with confidence limits (Clopper-

Table 1

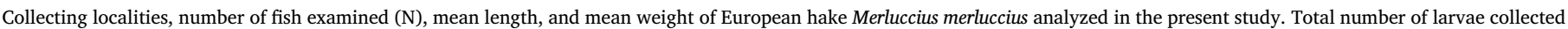
per area, and number of larvae genetically identified are reported too.

\begin{tabular}{|c|c|c|c|c|c|}
\hline & $\mathrm{N}$ fish & Mean length \pm SD (Range) & Mean weight \pm SD (Range) & $\mathrm{N}_{\text {coll }}$ collected larvae & $\mathrm{N}_{\mathrm{id}}$ identified larvae \\
\hline $\begin{array}{l}\text { NA - North Adriatic Sea } \\
\left(45^{\circ} 28^{\prime} \mathrm{N}-13^{\circ} 0^{\prime} \mathrm{E}\right)\end{array}$ & 73 & $\begin{array}{l}257.55 \pm 12.94 \\
(230-287)\end{array}$ & $\begin{array}{l}115.13 \pm 17.75 \\
(81-176)\end{array}$ & 669 & 50 \\
\hline $\begin{array}{l}\text { CA - Central Adriatic Sea - Italian coast } \\
\left(42^{\circ} 58^{\circ} \mathrm{N}-14^{\circ} 12^{\prime} \mathrm{E}\right)\end{array}$ & 137 & $\begin{array}{l}311.45 \pm 74.44 \\
(230-640)\end{array}$ & $\begin{array}{l}245.20 \pm 256.52 \\
(87-1800)\end{array}$ & 13562 & 130 \\
\hline $\begin{array}{l}\mathrm{CR}-\text { Central Adriatic Sea - Croatian coast } \\
\left(43^{\circ} 6^{\prime} \mathrm{N}-16^{\circ} 21^{\prime} \mathrm{E}\right)\end{array}$ & 257 & $\begin{array}{l}212.00 \pm 62.46 \\
(130-417)\end{array}$ & $\begin{array}{l}82.00 \pm 92.17 \\
(12-598)\end{array}$ & 4081 & 100 \\
\hline $\begin{array}{l}\text { SA - South Adriatic Sea } \\
\left(41^{\circ} 23^{\prime} \mathrm{N}-16^{\circ} 50^{\prime} \mathrm{E}\right)\end{array}$ & 46 & $\begin{array}{l}415.97 \pm 74.59 \\
(270-570)\end{array}$ & $\begin{array}{l}532.17 \pm 271.35 \\
(128-1236)\end{array}$ & 7237 & 81 \\
\hline $\begin{array}{l}\text { IO - Ionian Sea } \\
\left(37^{\circ} 49^{\prime} \mathrm{N}-20^{\circ} 16^{\prime} \mathrm{E}\right)\end{array}$ & 50 & $\begin{array}{l}470.20 \pm 124.12 \\
(315-370)\end{array}$ & $\begin{array}{l}1002.04 \pm 797.13 \\
(245-3200)\end{array}$ & 2045 & 75 \\
\hline $\begin{array}{l}\mathrm{EG}-\text { Aegean Sea } \\
\left(37^{\circ} 42^{\prime} \mathrm{N}-24^{\circ} 34^{\prime} \mathrm{E}\right)\end{array}$ & 27 & $\begin{array}{l}330.00 \pm 18.86 \\
(280-360)\end{array}$ & $\begin{array}{l}286.78 \pm 47.55 \\
(188-373)\end{array}$ & 69 & 30 \\
\hline $\begin{array}{l}\text { SS - South Sicily } \\
\left(37^{\circ} 78^{\prime} \mathrm{N}-12^{\circ} 29^{\prime} \mathrm{E}\right)\end{array}$ & 64 & $\begin{array}{l}286.73 \pm 47.17 \\
(240-460)\end{array}$ & $\begin{array}{l}193.87 \pm 128.22 \\
(100-765)\end{array}$ & 412 & 80 \\
\hline $\begin{array}{l}\text { CT - Central Tyrrhenian Sea } \\
\left(42^{\circ} 4^{\prime} \mathrm{N}-11^{\circ} 43^{\prime} \mathrm{E}\right)\end{array}$ & 165 & $\begin{array}{l}314.34 \pm 40.26 \\
(255-470)\end{array}$ & $\begin{array}{l}239.35 \pm 95.79 \\
(134-631)\end{array}$ & 230 & 100 \\
\hline $\begin{array}{l}\text { LI - Ligurian Sea } \\
\left(43^{\circ} 57^{\prime} \mathrm{N}-9^{\circ} 41^{\prime} \mathrm{E}\right)\end{array}$ & 76 & $\begin{array}{l}311.64 \pm 31.37 \\
(250-410)\end{array}$ & $\begin{array}{l}216.00 \pm 73.87 \\
(106-513)\end{array}$ & 41 & 35 \\
\hline $\begin{array}{l}\text { WS - West Sardinian Sea } \\
\left(40^{\circ} 28^{\prime} \mathrm{N}-08^{\circ} 05^{\prime} \mathrm{E}\right)\end{array}$ & 34 & $\begin{array}{l}331.47 \pm 83,43 \\
(260-540)\end{array}$ & $\begin{array}{l}349.91 \pm 314.36 \\
(147-1218)\end{array}$ & 314 & 106 \\
\hline $\begin{array}{l}\text { FR - Gulf of Lion } \\
\left(43^{\circ} 19^{\prime} \mathrm{N}-4^{\circ} 6^{\prime} \mathrm{E}\right)\end{array}$ & 49 & $\begin{array}{l}315.93 \pm 25.47 \\
(265-380)\end{array}$ & $\begin{array}{l}237.67 \pm 59.70 \\
(139-390)\end{array}$ & 11 & 5 \\
\hline $\begin{array}{l}\text { BAL - Balearic Sea } \\
\left(40^{\circ} 23^{\prime} \mathrm{N}-4^{\circ} 28^{\prime} \mathrm{E}\right)\end{array}$ & 30 & $\begin{array}{l}390.66 \pm 36.33 \\
(320-450)\end{array}$ & $\begin{array}{l}522.03 \pm 153.01 \\
(291-939)\end{array}$ & 23 & 15 \\
\hline $\begin{array}{l}\text { AL }- \text { Alboran Sea } \\
\left(36^{\circ} 34^{\prime} \mathrm{N}-3^{\circ} 30^{\prime} \mathrm{O}\right)\end{array}$ & 122 & $\begin{array}{l}309.82 \pm 41.13 \\
(255-470)\end{array}$ & $\begin{array}{l}236.61 \pm 111.10 \\
(123-982)\end{array}$ & 89 & 70 \\
\hline
\end{tabular}


Pearson), abundance (A), mean intensity (MI), and range of larvae present (min - max), following Bush et al. (1997), Rozsa et al. (2000) and Reiczigel (2003). They were estimated using the Quantitative Parasitology Qpweb software, implemented for the web (Reiczigel and Rozsa, 2005). The statistical significance of the differences observed in the prevalence and abundance values of the infection by Anisakis spp. larvae observed was assessed by the Fisher's exact test and Bootstrap $t$ test, respectively (Reiczigel and Rozsa, 2005). Differences were considered significant when $p<0.05$.

Subsequently, all the samplings data from different areas were pooled, and a Generalized Linear Models (GLMs) were implemented to test for the effect of sampling zone (A) and fish length (L) on the parasitic abundance (n). Abundance data were $\log$-transformed $(\log n$ +1 ), in order to fit a normal distribution. Two different GLMs were implemented to test for the effect of the explanatory variables and their dependence/independence: a) $\mathrm{GLM}_{1}$, independence between variables, b) $\mathrm{GLM}_{2}$, full dependence between variables. Models were compared by using the Akaike's information criterion (AIC, Burnham and Anderson 1998), and results were expressed as AIC differences ( $\triangle$ AIC), with the best model having $\triangle$ AIC $=0$.

Correlation between fish length and abundance values of the parasites in the viscera, ventral flesh, and dorsal flesh, were tested by means of a robust linear regression, designed to circumvent some limitations of traditional parametric and non-parametric approaches, when the distribution of errors is asymmetric or prone to outliers.

To test for the relationship between Fulton's K and Anisakis spp. abundance, a General Linear Model (GLM), which can accommodate for various non-normal error distributions of data, was run for the samples obtained from different geographic areas. For the parasitic abundance in fish, a logistic regression model with a binomial error distribution and logit link function was applied. Thus, the G statistic (i.e. the chisquared with one degree of freedom giving significance for the slope) was used to measure the difference in deviance between the full model and an additional GLM run where only the intercept was fitted.

\section{Results}

\subsection{Identification of Anisakis spp. and Hysterothylacium spp. larvae}

Anisakis spp. larvae ( $\mathrm{N}=28783)$, first identified to genus level, were subsequently recognized as larval Type I (28721) and Type II (62) on the basis of available morphological characters (sensu Berland, 1961).

According to the alleles observed at the diagnostic loci, i.e., Adk$2^{100}$, Pep C-1 $1^{100}$ and Pep $C-2^{100}$ (Mattiucci et al., 2014b), the subsample of 813 Anisakis type I larvae from all fish batches were assigned to the species A. pegreffii; according to the diagnostic alleles $A d k-2^{105}$, Pep C$1^{90}$ and Pep C-2 ${ }^{96}$ (Mattiucci et al., 2014b), one single larva was assigned to A. simplex (s. s.). Finally, 62 type II larvae resulted as $A$. physeteris according with diagnostic loci, i.e., $A d k-2^{97}, P e p C-1^{110}$ and Pep $C-2^{108}$ as indicated in Mattiucci et al., 2001. One single larva showed a heterozygote pattern between A. pegreffii and A. simplex (s. s.) at all the three allozyme diagnostic loci.

Anisakis specimens $(\mathrm{N}=150)$ previously identified by those diagnostic allozymes and sequenced at the nuclear elongation factor EF1 $\alpha$ 1 of nDNA, were recognized as belonging to A. pegreffii $(\mathrm{N}=0.149)$ or to A. simplex (s. s.) $(\mathrm{N}=0.1)$ (Fig. 3). Additionally, the same specimen $(\mathrm{N}=1)$ that showed a heterozygote pattern between alleles of $A$. pegreffii and A. simplex (s. s.) at the three allozyme diagnostic loci, had two peaks at both the two diagnostic positions of the EF1 $\alpha-1$ nDNA locus existing between the two Anisakis species (Fig. 3b); thus, two genetic markers agreed in identifying this individual as an F1 hybrid. The nuclear elongation factor EF1 $\alpha-1$ of nDNA sequences were deposited in GenBank (accession numbers: KY595203, KY595204, KY595205, KY595206, KY595207, KY595208, KY595209, KY595210 for A. pegreffii, MF374708 for A. simplex (s. s.), and MF358544 for the
F1 hybrid specimen).

Finally, Anisakis specimens $(\mathrm{N}=240)$ among those previously identified by allozyme diagnostic loci and EF $\alpha-1$ of nDNA, sequenced at the mtDNA cox 2 locus, confirmed the identification of $A$. pegreffii, $A$. simplex (s. s.) and A. physeteris in accordance with the previous results. The specimens matched, respectively, 100 or $99 \%$ with the $A$. pegreffii, A. simplex (s. s.) and A. physeteris sequences previously deposited in GenBank (Valentini et al., 2006 Mattiucci et al., 2014b). Phylogenetic analysis inferred from BI (Fig. 2) showed that those sequences $(\mathrm{N}=69)$ obtained at the mtDNA cox 2 gene from those Anisakis spp. larvae, clustered in a well supported clade also including the sequence of $A$. pegreffii, for that gene, previously obtained and deposited in GenBank. Similarly, the sequence of the single one specimen of $A$. simplex (s. s.) clustered in the clade represented by specimens of $A$. simplex (s. s.) sequenced in previous analyses and deposited in Genbank (Mattiucci et al., 2014b). Finally, A. physeteris sequences $(\mathrm{N}=9)$ clustered in the clade formed the previously deposited sequence of that species (Fig. 2).

The F1 hybrid between A. pegreffii and A. simplex (s. s.) detected by the two nuclear markers, when inferred from mtDNA cox2 sequence analysis, showed a matrilineage as A. pegreffii.

Sequences of mtDNA cox2 were deposited in GenBank (accession numbers: KY595195, KY595196, KY595197, KY595198, KY595199, KY595200, KY595201, KY595202 for A. pegreffii, KY595211, KY595212, KY595213 for A. physeteris, and MF358545 for A. simplex (s. s.)).

Besides larval specimens of Anisakis spp., 16 specimens of the raphidascaridid nematodes belonging to the genus Hysterothylacium spp., all detected in the visceral cavity of the fish host, were identified to the species level as $H$. aduncum. The sequences obtained ( $936 \mathrm{bp}$ ) matched at $99 \%$ with the ITS rDNA sequence of Hysterothylacium aduncum deposited in GenBank (JQ934878) (Smrzlić et al., 2012). Sequences of ITS rDNA for $H$. aduncum were deposited in GenBank under the accession numbers: KY595214, KY595215.

\subsection{Distribution of A. pegreffii by location, fish size and fishing ground}

A. pegreffii larvae were detected in the viscera, in the ventral, and in the dorsal flesh of the examined fish. They were recovered in syntopy with larval A. physeteris in the viscera of some of the hakes examined. Indeed, A. physeteris larvae were never found infecting the fish fillets. The single specimen belonging to the species $A$. simplex (s. s.) was recovered in syntopy with $A$. pegreffii in the viscera of the same individual fish host caught from the Alboran Sea. The F1 hybrid specimen so far identified was detected in this same batch of hake.

Data on prevalence (P) and mean abundance (A) of A. pegreffii larvae at different sites of infection (visceral cavity with internal organs and flesh) of the hakes examined, and their relative proportions in different fishing grounds of the Mediterranean Sea, are given in Table 2.

No statistically significant differences were observed in terms of prevalence and mean abundance of the infection with $A$. pegreffii between batches of hakes sampled from the same locality in different seasons of the year ( $p$ always $>0.05$ ). As a consequence, the data were pooled and identified only by the fishing grounds.

The overall levels of infection by $A$. pegreffii of hake samples originating from different Mediterranean fishing grounds showed different values $(p<0.001)$ (Table 2$)$. In addition, fish from each area resulted infected, even when showing different mean parasite abundances. Indeed, $A$. pegreffii exhibited the highest levels of infection both in prevalence $(P=100.0)$ and mean abundance $(A=157.3$, range 4-866) (Table 2) in hakes sampled in the southwest of the Adriatic Sea (SA sampling area 4 in Fig. 1, and Table 2). High levels of infection (prevalence $\mathrm{P}=89.8$; mean abundance $\mathrm{A}=98.9$ ) were recorded also in hakes sampled in the central western area of the Adriatic Sea (CA in Table 2), despite the average smaller size of the fish obtained from this area (mean fish length $=311.5 \mathrm{~cm}$ ). Remarkably high values of infection (prevalence $\mathrm{P}=91.8$; mean abundance $\mathrm{A}=15.88$ ) have also been 


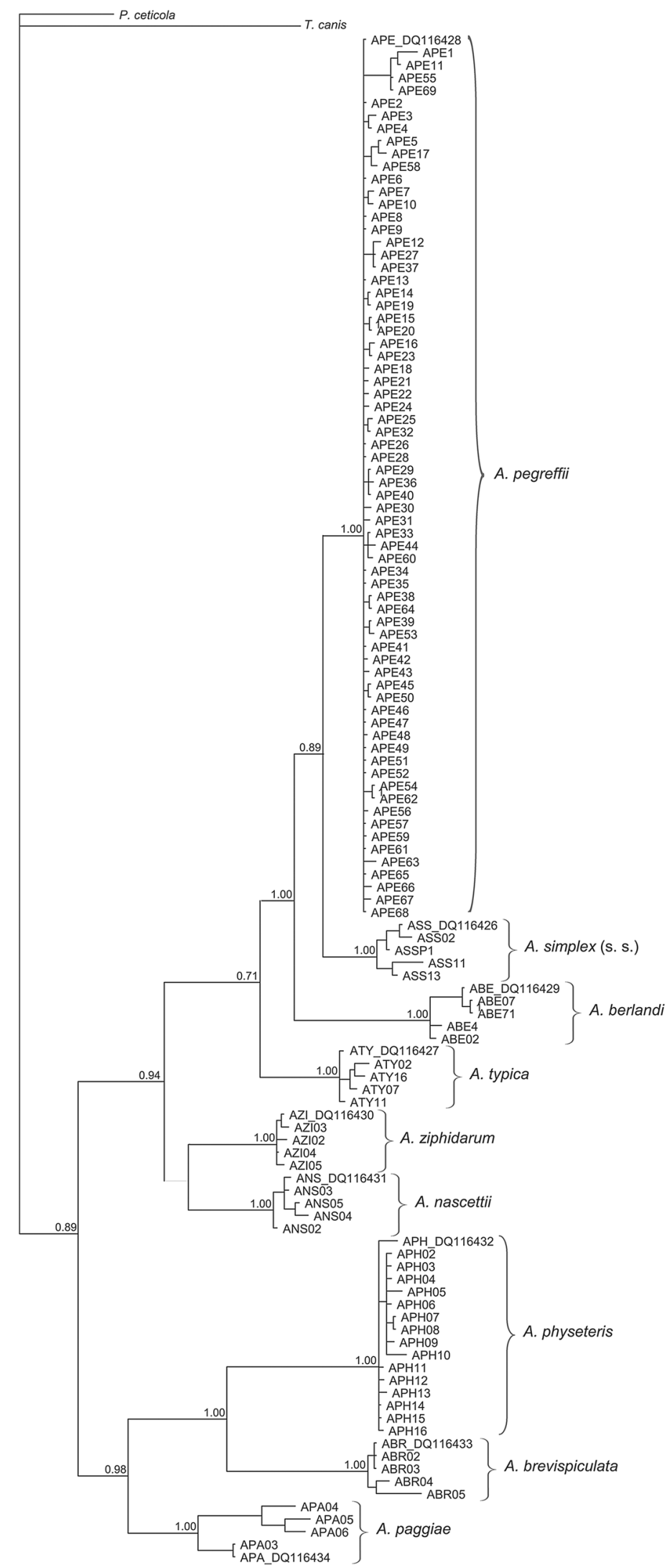

recorded in the central eastern Adriatic Sea (CR), in the northern area of the same basin (NA in Table 2, $\mathrm{P}=87.5$; $\mathrm{A}=9.29$ ), and in the Ionian Sea area, off Patras' coast (IO in Table 2, showing $\mathrm{P}=55.8$ and $\mathrm{A}=2.62$ values). Focusing on hake samples from different areas of the
Fig. 2. Bayesian inference (BI) tree based on mtDNA cox2 gene sequences of $A$. pegreffii larvae from M. merluccius sampled in the Mediterranean Sea, with respect to the other Anisakis spp. previously sequenced. The analysis was performed by MrBayes3.1 (Huelsenbeck and Ronquist, 2005), using TIM1 + I + G substitution model, as implemented in jModeltest2.1 (Darriba et al., 2012); the parameters for selected model are $\mathrm{I}=0.392$ and $\mathrm{G}=0.463$, calculated with Akaike Information Criterion (AIC) (Posada and Buckley, 2004)). For the Bayesian analysis, four incrementally heated Markov Chains (using default heating values), were run for 1,000,000 generations, sampling the Markov Chains at intervals of 100 generations. Numbers at the nodes are posterior probabilities. T. canis and P. ceticola were used as outgroups.
Adriatic Sea basin, we observed congruence across specific areas. Likewise, hakes from central Adriatic off the Italian coast (CA) and off the Croatian coast of Split (CR) showed similar prevalence $(\mathrm{P}=89.4$ and $\mathrm{P}=91.8$, respectively; $p=0.54$ ), but different mean abundance 
a)
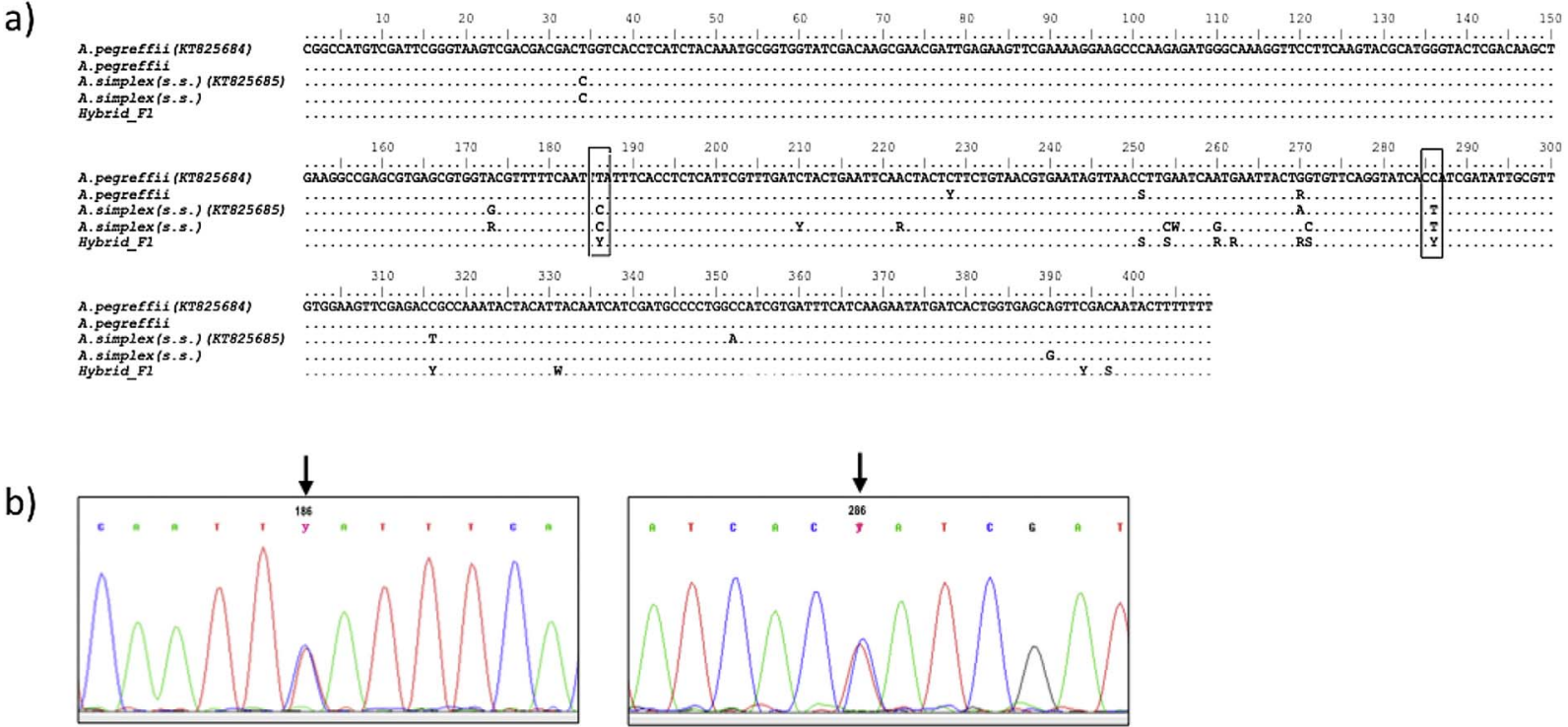

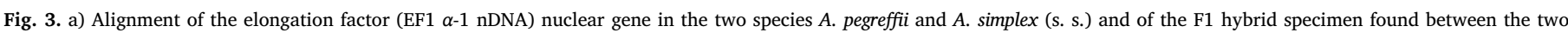

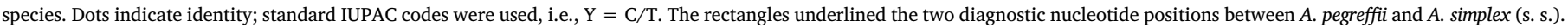
b) The heterozygote patterns of the F1 hybrid between the two species are highlighted by the arrows at the two diagnostic nucleotide positions (bp 186 and 286).

levels $(\mathrm{A}=32.20$ and $\mathrm{A}=13.72$, respectively; $p=0.001$ ), whereas the mean length of the hakes differed $(311.45 \pm 74.44 \mathrm{~cm}$ and $212.00 \pm 62.46 \mathrm{~cm}$, respectively $p<0.01$ ) (Table 1 ).

Overall, the hake samples from the other fishing grounds of the western Mediterranean Sea showed lower levels of infection compared to the fish originating from the Adriatic/Ionian area, with statistically significant differences in term of prevalence and abundance of infection $(p<0.05)$ (Table 2).

Concerning the western sampling sites of the Mediterranean Sea, higher levels of infection, in term of prevalence and abundance of infection, have been recorded in hakes sampled in the waters off the South of Sicily (SS in Table 2, P = 57.8; A = 6.4) and in the North West of Sardinian Sea (WS in Table 2, P = 55.9; A = 9.1). The samples from the Alboran Sea, Balearic Sea, Ligurian Sea and Gulf of Lion showed the lowest levels of infection, including both prevalence and abundance (Table 2).

The distribution of $A$. pegreffii larvae by site of the infection in the host, such as liver, viscera, ventral flesh and dorsal flesh, was reported as relative frequency of larvae counted per site. No statistically significant differences after a Mann-Whitney test $(\mathrm{p}>0.05)$ was found among the relative frequencies observed in each hake sample from different localities. Thus, the relative proportions of $A$. pegreffii by infection sites in the fish host was cumulated for the different batches, and resulted as following: $28.3 \%$ of $A$. pegreffii larvae were detected in the fish liver, whereas $62.9 \%$ in the rest of the host's viscera; $6.6 \%$ in the ventral part of the fish flesh and $2.1 \%$ in the dorsal flesh of infected hakes.

Taking into account the whole sample of hakes, the best model explaining the parasitic burden by A. pegreffii in M. merluccius was the $\mathrm{GLM}_{2}$. This model yielded a correlation between the abundance of parasites and both the fish length (L) and the sampling area (A). Indeed, differences in length have been found between hakes from different fishing grounds of the Mediterranean Sea (Student's $t$-test, $t=15.32$, $p<0.001)$. A significant correlation $\left(r^{2}=0.349, p<0.001\right)$ between fish length (L) and number of parasites (n) resulted by a Spearman correlation analysis, with the total (flesh and viscera) number of larvae increasing with the length of the fish host (Fig. 4). A significant correlation was also recorded between fish length and the number of larvae detected in the ventral flesh $\left(r^{2}=0.284, p<0.001\right)$, and between fish length and the number of larvae detected in the dorsal flesh $\left(r^{2}=0.193, p<0.001\right)$. Moreover, a significant correlation was recorded between the value of the parasitic abundance observed in the ventral flesh with those detected in the dorsal flesh $\left(r^{2}=0.322\right.$, $p<0.01$ ), and finally between the abundance value recorded in the viscera of the fish with respect of those estimated in the fish flesh $\left(r^{2}=0.345, p<0.01\right)$.

According to the results obtained by the $\mathrm{GLM}_{3}$ model, the main variables associated with the $A$. pegreffii parasite burden in hake samples were fish length and fishing ground. Fulton $\mathrm{K}$ parameter, related to the body condition index (BCI) of the fish, did not show any significant correlation when related with the abundance of $A$. pegreffii infection.

\subsection{Distribution of A. physeteris and $H$. aduncum larvae by site of infection, fish length and fishing ground}

A total of 62 Anisakis type II larvae identified by genetic/molecular markers as belonging to $A$. physeteris species were found in hakes sampled from some of the fishing grounds. The highest levels of infection by $A$. physeteris was recorded in the Alboran Sea, where a prevalence $\mathrm{P}=13.9$ and abundance $\mathrm{A}=0.35$ values of the infection by that parasite species were recorded. A small number of $A$. physeteris larvae $(<10$ specimens per area) were also detected in fish sampled at WS, IO, CT.

Hysterothylacium spp. larvae were sporadically detected $(\mathrm{N}=17)$ only in M. merluccius sampled in the Adriatic Sea area (CR and SA), showing low levels of infection. All the larvae of Hysterothylacium spp. detected were found in the visceral cavity of the fish host.

\section{Discussion}

Larval specimens belonging to three species of Anisakis (i.e. A. pegreffii, A. physeteris, and A. simplex (s. s.)) were identified in a large sample of European hakes obtained from 13 different fishing grounds of the Mediterranean Sea. A. pegreffii was detected in fish collected from all fishing grounds; it also occurred in sympatry and syntopy with $A$. physeteris from hakes fished in four sampling areas (AL, SA, IO, CT) (Fig. 1). The only A. simplex (s. s.) larva identified was collected in a fish from the Alboran Sea (AL), in syntopy with other A. pegreffii larvae. A. simplex (s. s.) was reported with higher frequencies in this area of the Mediterranean Sea always in sympatry with $A$. pegreffii in previous studies (Mattiucci et al., 2004), but also in parasitological surveys of other fish species, such as Lepidopus caudatus and Lophius piscatorius, 
Table 2

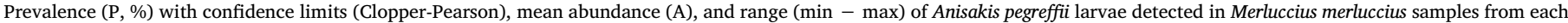
sampling areas. Number of total larvae $\left(\mathrm{N}_{\text {Tot }}\right)$ and their relative proportions (\%) in different tissues are also given.

\begin{tabular}{|c|c|c|c|c|c|c|c|}
\hline & & NA & CA & CR & SA & IO & EG \\
\hline \multirow[t]{5}{*}{ Viscera } & N FISH & 73 & 137 & 257 & 46 & 50 & 27 \\
\hline & $\mathrm{P} \%$ & 84.7 & 89.8 & 89.9 & 100.0 & 90.0 & 74.1 \\
\hline & & $0.743-0.921$ & $0.833-0.939$ & $0.855-0.930$ & $0.932-1.000$ & $0.782-0.367$ & $0.430-0.798$ \\
\hline & $\begin{array}{l}\text { A } \\
\text { (RANGE) }\end{array}$ & $\begin{array}{l}7.86 \pm 7.19 \\
(2-31)\end{array}$ & $\begin{array}{l}96.09 \pm 362.41 \\
(1-3005)\end{array}$ & $\begin{array}{l}14.34 \pm 40.14 \\
(1-383)\end{array}$ & $\begin{array}{l}145.5 \pm 167.73 \\
(3-773)\end{array}$ & $\begin{array}{l}40.14 \pm 109.30 \\
(1-602)\end{array}$ & $\begin{array}{l}2.22 \pm 2.14 \\
(1-7)\end{array}$ \\
\hline & Tot $(\%)$ & $566(84.6 \%)$ & $13165(97.1 \%)$ & $3685(90.3 \%)$ & $6697(92.5 \%)$ & $2007(98.1 \%)$ & $60(87.0 \%)$ \\
\hline \multirow[t]{5}{*}{ Ventral flesh } & $\mathrm{P} \%$ & 48.6 & 51.8 & 19.8 & 87.0 & 28.8 & 19.2 \\
\hline & & $0.36-0.60$ & $0.434-0.602$ & $0.152-0.252$ & $0.737-0.951$ & $0.162-0.425$ & $0.102-0.415$ \\
\hline & A & $0.86 \pm 7.86$ & $2.35 \pm 4.25$ & $0.33 \pm 0.83$ & $8.63 \pm 13.74$ & $0.66 \pm 1.35$ & $0.23 \pm 0.51$ \\
\hline & (RANGE) & $(1-5)$ & $(1-29)$ & $(1-17)$ & $(1-62)$ & $(1-7)$ & $(1-2)$ \\
\hline & Tot $(\%)$ & $71(10.6 \%)$ & $322(2.4 \%)$ & $86(2.1 \%)$ & $397(5.5 \%)$ & $33(1.7 \%)$ & $7(10.1 \%)$ \\
\hline \multirow[t]{4}{*}{ Dorsal flesh } & $\mathrm{P} \%$ & 22.2 & 33.6 & 40.1 & 65.2 & 8.0 & 7.4 \\
\hline & & $0.13-0.22$ & $0.258-0.419$ & $0.342-0.463$ & $0.498-0.786$ & $0.022-0.192$ & $0.13-0.237$ \\
\hline & $\begin{array}{l}\text { A } \\
\text { (RANGE) }\end{array}$ & $\begin{array}{l}0.44 \pm 1.02 \\
(1-5)\end{array}$ & $\begin{array}{l}0.55 \pm 1.01 \\
(1-6)\end{array}$ & $\begin{array}{l}1.206 \pm 2.615 \\
(1-6)\end{array}$ & $\begin{array}{l}3.11 \pm 6.25 \\
(1-31)\end{array}$ & $\begin{array}{l}0.100 \pm 0.30 \\
(1-2)\end{array}$ & $\begin{array}{l}0.07 \pm 0.27 \\
(1-1)\end{array}$ \\
\hline & Tot $(\%)$ & $32(4.8 \%)$ & $75(0.5 \%)$ & $310(7.6 \%)$ & $143(2.0 \%)$ & $5(0.2 \%)$ & $2(2.9 \%)$ \\
\hline \multirow[t]{5}{*}{ Total } & $\mathrm{P} \%$ & 87.5 & 89.8 & 91.8 & 100.0 & 94.0 & 81.5 \\
\hline & & $0.77-0.94$ & $0.837-0.940$ & $0.879-0.947$ & $0.932-1.000$ & $0.835-0.987$ & $0.538-0.876$ \\
\hline & $\begin{array}{l}\text { A } \\
\text { (RANGE) }\end{array}$ & $\begin{array}{l}9.29 \pm 8.05 \\
(1-34)\end{array}$ & $\begin{array}{l}98.9 \pm 366.13 \\
(2-3037)\end{array}$ & $\begin{array}{l}15.88 \pm 41.80 \\
(1-399)\end{array}$ & $\begin{array}{l}157.32 \pm 182.56 \\
(4-866)\end{array}$ & $40.90 \pm 110.18$ & $2.55 \pm 2.25$ \\
\hline & TOT & 669 & 13562 & 4081 & 7237 & 2045 & 69 \\
\hline & SS & CT & LI & WS & FR & BAL & $\mathrm{AL}$ \\
\hline \multirow[t]{5}{*}{ Viscera } & 64 & 165 & 76 & 34 & 49 & 30 & 122 \\
\hline & 51.6 & 40.6 & 25.0 & 55.9 & 14.3 & 41.9 & 11.8 \\
\hline & $0.390-0.639$ & $0.330-0.485$ & $0.158-0.363$ & $0.381-0.724$ & $0.059-0.272$ & $0.245-0.609$ & $0.191-0.347$ \\
\hline & $\begin{array}{l}5.84 \pm 15.51 \\
(1-98)\end{array}$ & $\begin{array}{l}1.28 \pm 2.50 \\
(1-17)\end{array}$ & $\begin{array}{l}0.50 \pm 1.27 \\
(1-7)\end{array}$ & $\begin{array}{l}8.58 \pm 24.09 \\
(1-121)\end{array}$ & $\begin{array}{l}0.16 \pm 0.43 \\
(1-2)\end{array}$ & $\begin{array}{l}0.74 \pm 1.26 \\
(1-6)\end{array}$ & $\begin{array}{l}0.62 \pm 1.27 \\
(1-3)\end{array}$ \\
\hline & $374(90.1 \%)$ & $211(91.7 \%)$ & $38(92.7 \%)$ & $292(92.9 \%)$ & $8(72.7 \%)$ & $23(100.0 \%)$ & $76(85.4 \%)$ \\
\hline \multirow[t]{5}{*}{ Ventral flesh } & 26.6 & 6.1 & 2.6 & 23.5 & 6.1 & 0.0 & 7.4 \\
\hline & $0.170-0.390$ & $0.029-0.109$ & $0.003-0.092$ & $0.114-0.411$ & $0.013-0.169$ & $0.000-0.000$ & $0.037-0.133$ \\
\hline & $0.14 \pm 0.69$ & $0.08 \pm 0.37$ & $0.02 \pm 0.16$ & $0.44 \pm 0.92$ & $0.06 \pm 0.24$ & $0.00 \pm 0.00$ & $0.10 \pm 0.37$ \\
\hline & $(1-9)$ & $(1-3)$ & $(1-1)$ & $(1-4)$ & $(0-1)$ & $(0-0)$ & $(1-2)$ \\
\hline & $29(7.0 \%)$ & $14(6.1 \%)$ & $2(4.9 \%)$ & $19(6.1 \%)$ & $3(27.3 \%)$ & 0 & $12(13.5 \%)$ \\
\hline \multirow[t]{5}{*}{ Dorsal flesh } & 6.30 & 3.0 & 1.3 & 8.8 & 0.0 & 0.0 & 0.8 \\
\hline & $0.022-0.154$ & $0.010-0.069$ & $0.000-0.071$ & $0.024-0.232$ & $0.000-0.073$ & $0.000-0.112$ & $0.000-0.042$ \\
\hline & $0.14 \pm 0.69$ & $0.03 \pm 0.17$ & $0.01 \pm 0.11$ & $0.08 \pm 0.28$ & $0.00 \pm 0.00$ & $0.00 \pm 0.00$ & $0.01 \pm 0.09$ \\
\hline & $(1-5)$ & $(1-1)$ & $(1-1)$ & $(1-3)$ & $(0-0)$ & $(0-0)$ & $(1-1)$ \\
\hline & $9(2.9 \%)$ & $5(2.2 \%)$ & $1(2.4 \%)$ & $3(1.0 \%)$ & 0 & 0 & $1(1.1 \%)$ \\
\hline \multirow[t]{5}{*}{ Total } & 57.8 & 44.2 & 27.6 & 55.9 & 20.4 & 41.9 & 26.2 \\
\hline & $0.453-0.697$ & $0.365-0.525$ & $0.180-0.391$ & $0.381-0.724$ & $0.102-0.343$ & $0.245-0.609$ & $0.203-0.364$ \\
\hline & $6.43 \pm 16.50$ & $1.39 \pm 2.56$ & $0.54 \pm 1.29$ & $9.11 \pm 24.81$ & $0.22 \pm 0.47$ & $0.74 \pm 1.26$ & $0.73 \pm 1.47$ \\
\hline & $(1-98)$ & $(1-17)$ & $(1-7)$ & $(1-124)$ & $(1-2)$ & $(1-6)$ & $(1-3)$ \\
\hline & 412 & 230 & 41 & 314 & 11 & 23 & 89 \\
\hline
\end{tabular}

run in the framework of the PARASITE Project (introduction paper of this special issue, Levsen et al., in press). In the same sample from the Alboran Sea, also a F1 hybrid between A. pegreffii and A. simplex (s. s.) was found, having a matrilineage as $A$. pegreffii (inferred from mtDNA $\operatorname{cox} 2$ sequence analysis, data not shown). The detected $\mathrm{F} 1$ individual is the result of a current hybridization event in a sympatric area of the two species in the Mediterranean Sea. On the other hand, Alboran Sea represents an oceanographic transition zone between Atlantic Ocean and Mediterranean Sea (Tintore et al., 1988). From this water basin, other Anisakis spp. larvae have been recorded in other fish species (Mattiucci et al., 2014a; Levsen et al., in press).

Anisakis pegreffii infection exhibited significantly higher values of infection than $A$. physeteris in hakes from all sampled fishing grounds. The highest values of prevalence $(\mathrm{P}=13.9)$ and abundance $(\mathrm{A}=0.35)$ for $A$. physeteris were recorded in the Alboran Sea. These values were lower than those detected for $A$. pegreffii $(\mathrm{P}=26.2 ; \mathrm{A}=0.73)$ infection from the same fishing ground. In all other sampling areas, A. pegreffii larvae outnumbered $A$. physeteris. The overall higher levels of infection by $A$. pegreffii, with respect to $A$. physeteris, are generally similar to those previously reported for these two species in European hake from the same fishing grounds (Table 3) (Mattiucci et al., 2004), even though the levels of infection in the flesh of this fish species were previously not reported, thus slightly underestimating the quantification of $A$. pegreffii in the Mediterranean hakes. Furthermore, A. pegreffii larvae occurred in the viscera and flesh of the fish, whereas all the larvae of $A$. physeteris were found only in the viscera (mostly embedded in the liver) of the host. It can be therefore hypothesized that the latter species is not capable of migrating in the musculature of the fish.

The parasitic levels of infection by $A$. pegreffii recorded in our $M$. merluccius samples from different fishing grounds throughout the Mediterranean Sea were extremely heterogeneous, and in agreement with the scarce literature data present so far (Table 3 ). This different 


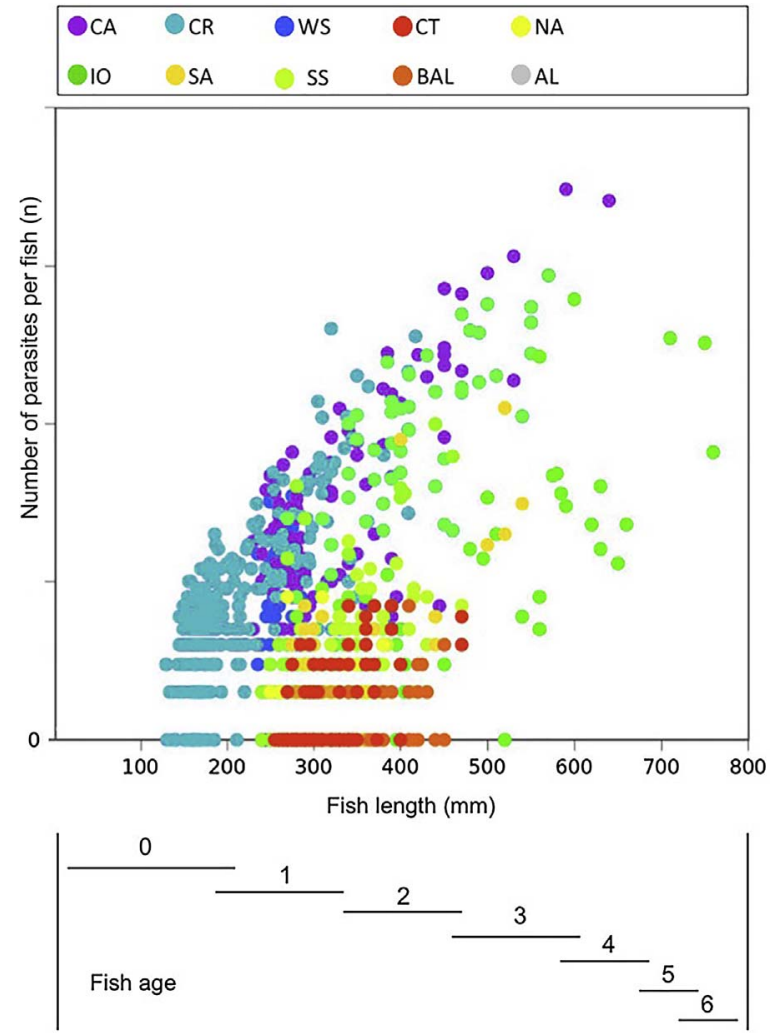

Fig. 4. Spearman correlation analysis $\left(r^{2}=0.349, p<0.001\right)$ between fish total length $(\mathrm{mm})$ and number of parasites per fish (n). Below, estimate of the fish age based on length, according to Mellon-Duval et al., 2010. Colour spots are associated to the different sampling localities, as indicated above.

parasitic burden recorded in different fish samples seemed to be addressed by two drivers of the infection: the fish size and the fishing ground. The best model explaining the parasitic burden by $A$. pegreffii recorded in hakes was the $\mathrm{GLM}_{2}$, which highlighted the correlation between the abundance of parasites with both the fish length (L) and the sampling area (A). In our samples, the fish length was the main variable related to the abundance of this parasite species.

Likewise, hakes from the western and eastern part of the central Adriatic Sea showed similar prevalence $(\mathrm{P}=89.4$ and $\mathrm{P}=91.8$; $p=0.54)$ but different mean abundance values ( $\mathrm{A}=32.20$ and $\mathrm{A}=13.72, p=0.001$ respectively in hakes from Italian coasts versus Croatian ones). Thus, this difference in abundance of larvae could be explained by the highest length recorded for the fish obtained off the Italian coast compared to the batch originating from the Croatian coast (311.45 $\pm 74.44 \mathrm{~cm}$ and $212.00 \pm 62.46 \mathrm{~cm}, p<0.01$ ). In all $M$. merluccius samples examined, larger fish tended to show (flesh plus viscera) a higher abundance of the parasite (Spearman correlation $r^{2}=0.349, p<0.001$, Fig. 2) (Fig. 2) (length/age relation was estimated by Mellon-Duval et al., 2010, fitting a von Bertalanffy model to data obtained from recaptured fish, in the Gulf of Lion). Considering the whole examined sample of $M$. merluccius and analyzing it with a higher A. pegreffii burden, it is evident that these specimens corresponded to the 4th-7th year of age (range: $60 \mathrm{~cm}-80 \mathrm{~cm}$ of length) (Fig. 2) suggesting a direct relation with feeding habits of the fish, preying upon zooplanktonic organisms and other fish species that act as hosts of $A$. pegreffii larvae. Considering that once $A$. pegreffii larvae accumulate in the fish host, where they probably remain an undetermined time, the correlation between the size of the fish and the parasitic burden is a direct consequence of the time that the fish spent feeding on its prey. Hake is a top predator that occupies different trophic levels during its life, and its diet shifts from euphausiids and decapods, consumed by the smaller individuals $(<16 \mathrm{~cm} \mathrm{TL}$ ), to fishes consumed by larger individuals (Carpentieri et al., 2005). Before the full transition to the ichthyophagous phase, hake showed more generalized feeding habits where decapods, benthic (Gobiidae, Callionymus spp., Arnoglossus spp.) and nectonic fish (Sardina pilchardus, Engraulis encrasicolus) are predominant in the diet, whereas cephalopods have a lower incidence (Carpentieri et al., 2005).

In some larger hakes fished in central Adriatic Sea (CA), the highest amount of larvae per single infected fish was recorded: a $59 \mathrm{~cm}$ long specimen harboured 3037 larvae, of which 3005 were located in the viscera and 22 in the muscular part. Also in the Ionian Sea off Patras (IO), some fish of large size showed high levels of infection; 608 larvae were counted in a single hake, whose length was $60 \mathrm{~cm}$ (Fig. 2).

The geographical areas too, with their ecological conditions and the presence of suitable hosts for the life cycle of the Anisakis spp., seem to represent a determinant driver of $A$. pegreffii rate of infection. Previous authors (Valero et al., 2006; Mattiucci et al., 2004, 2014b; Suzuki et al., 2010; Cipriani et al., 2017) noted that levels of infection by different species of Anisakis vary depending on the geographical origin of the fish host. In fact, remarkably higher levels of infection for A. pegreffii were recorded in hakes of the Adriatic Sea/Ionian Sea areas compared to the fish of the same size range obtained from the western Mediterranean fishing grounds. The highest levels of infection (both in prevalence $\mathrm{P}=100.0$ and mean abundance $\mathrm{A}=157.3$, range 4-866; Table 2) were recorded in hakes fished off the Italian coasts of the southern area of the Adriatic Sea (SA - sampling area 4 in Fig. 1, and Tables 1 and 2). Notably, the sample of fish from this area was larger (mean length $415.97 \mathrm{~cm}$ ) (SA in Table 1) compared with the other fish batches of the Adriatic Sea (CA and CR in Table 1) $(p<0.001)$. High levels of infection have been also recorded in hakes caught off the Italian coasts of the central area of the Adriatic Sea (prevalence $P=89.8$ and mean abundance $A=98.9$ ), despite of the overall smaller size of fish sampled in this area (mean length $311,5 \mathrm{~cm}$, CA in Table 1).

Concerning the western Mediterranean fishing ground, the hakes sampled from the central Tyrrhenian Sea (CT) showed low levels of infection of A. pegreffii (Table 2), with values comparable to those obtained in samples from Aegean Sea (AEG), Ligurian Sea (LI) and Balearic Sea (BAL) $(p>0.05)$ (Table 2).

The eastern basin of the Mediterranean Sea, in particular the central and southern area of the Adriatic Sea, appears as a "hotspot" for the presence of A. pegreffii. This statement is supported by data recorded for other fish species, like Engraulis engraulis (Cipriani et al., 2016, 2017) and Sardina pilchardus (Levsen et al., in press), showing the highest levels of infection in this western part of the Mediterranean Sea (Table 2). This finding could be related to ecological characteristics of the Adriatic Sea, with both abiotic and biotic conditions favourable to maintain the life cycle of $A$. pegreffii at high population size (see Cipriani et al., 2017). Some favourable abiotic conditions of the central Adriatic Sea, which favour the presence of a stable food web, may result in enhancing the overlapped and abundant distribution of hosts belonging to different trophic levels of the life cycle of A. pegreffii, and could thus explain its pattern of distribution and high levels of infection in different fish species, such as hakes, anchovies (present issue Cipriani et al., 2017), and sardines (Levsen et al., in press), in this semi-enclosed and narrow basin. Abiotic and biotic factors, such as mean sea surface temperature, depth, salinity, sea surface temperature range, as well as primary production, were identified as most important abiotic variables impacting the distribution of Anisakis spp. (Højgaard, 1998; Kuhn et al., 2016).

A further hypothesis to explain the high densities of A. pegreffii recorded in this basin could be the presence of an "anthropogenic shortcut" in the life cycle of the parasite (see Cipriani et al., 2017). There is a widely used routine, followed by local fishermen, who eviscerate fish (above all hakes and scabbard fish) directly on board of the vessels, then discard the viscera at sea, together with bycatches. This practice seems related to the necessary removal of viscera in fish species largely infected by Anisakis larvae, whose presence would 
Table 3

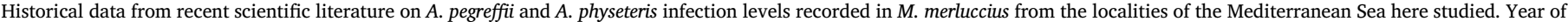
sampling, number of fish examined $\left(\mathrm{N}_{\text {fish }}\right)$ with fish mean length (n. r. stands for not reported), Prevalence (P) and Abundance (A) are reported.

\begin{tabular}{|c|c|c|c|c|c|c|c|}
\hline \multirow[t]{2}{*}{ Fishing area } & \multirow[t]{2}{*}{ Year of sampling } & \multirow[t]{2}{*}{$\mathrm{N}_{\text {fish }}$ mean length (mm) } & \multicolumn{2}{|c|}{ A. pegreffii } & \multicolumn{2}{|c|}{ A. physeteris } & \multirow[t]{2}{*}{ Author } \\
\hline & & & $\mathrm{P}$ & A & $\mathrm{P}$ & A & \\
\hline Croatian coast & 2014 & $120(342.92 \mathrm{~mm})$ & 70.8 & 6.87 & - & - & Mladineo and Poljak (2014) \\
\hline West Sardinian Sea & 2014 & $96(200.00 \mathrm{~mm})$ & 37.5 & - & 1.0 & - & Piras et al. (2014) \\
\hline Sardinian Sea & 2011 & 50 (n. r.) & 30.0 & 0.5 & - & - & Angelucci et al. (2011) \\
\hline Sardinian Sea & 2011 & 50 (n. r.) & - & 0.32 & - & - & Meloni et al. (2011) \\
\hline Alboran Sea & 1994 & $63(450.00 \mathrm{~mm})$ & 0.71 & - & 0.01 & - & Valero et al. (2006) \\
\hline Aegean Sea & 2012 & $10(262.00 \mathrm{~mm})$ & 80.0 & 9.6 & - & - & Pekmezci et al. (2014) \\
\hline Ionian Sea & 2004 & 53 (n. r.) & 94.2 & 30.4 & 3.3 & 0.1 & Mattiucci et al. (2004) \\
\hline Adriatic Sea & 2004 & 60 (n. r.) & 73.3 & 10.0 & - & - & Mattiucci et al. (2004) \\
\hline Tyrrhenian Sea & 2004 & 67 (n. r.) & 35.8 & 0.8 & 6.0 & 0.1 & Mattiucci et al. (2004) \\
\hline Ligurian Sea & 2004 & 84 (n. r.) & 63.8 & 71.7 & 3.6 & 0.1 & Mattiucci et al. (2004) \\
\hline Balearic Sea & 2004 & 77 (n. r.) & 8.3 & 0.1 & 31.6 & 0.6 & Mattiucci et al. (2004) \\
\hline Aegean Sea & 2004 & 90 (n. r.) & 54.4 & 12.1 & 1.1 & 0.1 & Mattiucci et al. (2004) \\
\hline
\end{tabular}

compromise the value of the fish at landing. At the beginning of this study, we had several problems in obtaining "intact" hake specimens, because most fishermen had the habit of removing part of the viscera of hake straight onboard of trawlers, ripping away gills and linked organs straight from the gills holes, without cutting the fish directly. These viscera discards, originating from various commercial fish species of that area, would have been dropped at sea together with the common bycatch discards, including still alive Anisakis larvae. Once at sea, these discards may represent a food source for fish, cetaceans and seabirds, that may eventually acquire Anisakis larvae present; it is in fact suggested that discards from fishing may increase the parasite transmission to the next host (Oro and Ruiz, 1997; Morton and Yuen, 2000; Arcos et al., 2001; Bozzano and Sardà, 2002). In Northern areas of the Adriatic Sea dolphins distribution overlaps with areas used intensively by fishermen and many sightings were recorded during interactions with fishery (Genov et al., 2008), when dolphins have been observed feeding on discarded fish as well (Bearzi et al., 2008). Animals follow working nets (feeding on stirred-up organisms or fish gilled in mesh) and also feed on discarded by-catch (Fertl and Leatherwood, 1997). We therefore hypothesize that fish and dolphins feeding on these by-catches discarded at sea, belonging to the same heavily parasitized fish of the batch we inspected, could acquire greater amount of Anisakis individuals, enhancing this "anthropogenic shortcut" in the parasite cycle.

According to the GLMs models, no statistically significant correlation was found between the Fulton K BCI of the hakes and the A. pegreffii abundance ( $\mathrm{p}>0.05$ ). Both fish from heavily infected stocks and even fish that resulted not infected, maintained a constant proportion in weight and length, showing no change in their body condition index (BCI), and thus likely suggesting that these larval parasites have no pathogenic impact on the fish health status.

Since M. merluccius is one of the most important European fish species caught off western Europe, this study offers a crucial food safety device for assessing risks associated with these parasites in hakes from several fishing areas of the Mediterranean Sea. The fillets, as the edible part of the fish, represent the real risk to the consumer when harbouring zoonotic Anisakis larvae. Even if there is no evidence of large consumption of raw hake meat in the European Mediterranean countries, as it happens for anchovies or sardines, the exact information on larval localization in the fish product should be provided for a detailed risk assessment to the consumer (Bao et al., 2017). At least, not only live larvae could cause the parasitic zoonosis (human anisakiasis), but even dead larvae could provoke allergic symptoms in sensitized patients (Audicana and Kennedy, 2008). Therefore, an accurate examination of the fish flesh permits a real assessment of the parasitic levels of infection to better evaluate the real threat of human infection. A significant correlation was recorded between the abundance of $A$. pegreffii larvae present in the viscera of the hakes and the larvae counted in the flesh $\left(r^{2}=0.345, p<0.01\right)$. This result is consistent with similar observations reported by Karl and Levsen (2011) in grey gurnards infected by A. simplex (s. s.). Indeed, these authors reported in this fish “...a significantly positive relationship between both abundance and intensity of the larvae (A. simplex (s. s.)) in the flesh and the viscera $(r=0.64$ and $r=0.59$, respectively), i.e. the number of larvae in the flesh tend to increase with increasing infection level in the viscera...").

Only $2.5 \%$ of the fish positive for $A$. pegreffii exhibited an infection in the flesh and no larvae in the viscera, with a maximum number of three larvae detected in the ventral part of the fillet. Karl and Levsen, 2011 reported a similar observation on a different Anisakis species infecting a different fish host, with the $1.8 \%$ of $A$. simplex (s. s.) larvae being in flesh of grey gurnard, but not in viscera. Those authors emphasized that fish which "appear to be free of nematodes in the viscera may still carry A. simplex larvae in the flesh, i.e. the larval infection level in the viscera cannot be used as reliable indicator for the approximate Anisakis burden in the flesh (Karl and Levsen, 2011)".

Finally, the correct genetic/molecular identification of the anisakid nematodes involved in the fish infection represents the basis for any epidemiological survey intended to identify the zoonotic species involved and enhances the possibility to provide an accurate human risk assessment. Different Anisakis species showed different capacities of migrating in the muscular edible part of the fish, aspect that involves a different zoonotic potential. For example, A. physeteris was never reported in the fish flesh. In addition, no human cases of anisakiasis have been so far recorded as caused by this species. Data so far acquired suggest that $A$. pegreffii and $A$. simplex (s. s.) differ in their site of infection in the fish host, with A. simplex (s. s.) showing a higher propensity to invade the flesh respect to A. pegreffii (Quiazon et al., 2011; Cipriani et al., 2015), even if both species resulted to be zoonotic (D'Amelio et al., 1999; Umehara et al., 2007; Fumarola et al., 2009; Mattiucci et al., 2011, 2013, 2017b; Arai et al., 2014; Lim et al., 2015; Mladineo et al., 2016).

\section{Acknowledgments}

The research was carried out with funding received from the "European Union's Seventh Framework Programme for research, technological development and demonstration", under the grant agreement no. 312068 "PARASITE". We would also like to thank the anonymous referees for their valuable contribution to the editing of this manuscript.

\section{References}

Abaunza, P., Mattiucci, S., Nascetti, G., Magoulas, A., Cimmaruta, R., Bullini, L., 2001. Morphometric and meristic variation in European hake, Merluccius merluccius, from 
the Northeast Atlantic and Mediterranean Sea. ICES Document CM 2001/J:01 20. Alheit, J., Pitcher, T.J., 1995. Hake: Fisheries, Ecology and Markets. Springer, London. Angelucci, G., Meloni, M., Merella, P., Sardu, F., Madeddu, S., Marrosu, R., Petza, F., Salati, F., 2011. Prevalence of Anisakis spp. and Hysterothylacium spp. larvae in teleosts and cephalopods sampled from waters off Sardinia. J. Food Prot. 74 1769-1775.

Arcos, J.M., Oro, D., Sol, D., 2001. Competition between the yellow-legged gull Larus cachinnans and Audouin's gull Larus audouinii associated with commercial fishing vessels: the influence of season and fishing fleet. Mar. Biol. 139, 807-816.

Ardizzone, G.D., Corsi, F., 1997. Atlas of Italian demersal fishery resources. Biol. Mar. Medit. 4, 568.

Audicana, M.T., Kennedy, M.V., 2008. Anisakis simplex: from obscure infectious worm to inducer of immune hypersensitivity. Clin. Microbiol. 21, 360-369.

Bao, M., Pierce, G.J., Pascual, S., González-Muñoz, M., Mattiucci, S., Mladineo, I., Cipriani, P., Bušelić, I., Strachan, N.J.C., 2017. Assessing the risk of an emerging zoonosis of worldwide concern: anisakiasis. Sci. Rep. 7, 43699.

Bearzi, G., Fortuna, C.M., Reeves, R.R., 2008. Ecology and conservation of common bottlenose dolphins Tursiops truncatus in the Mediterranean Sea. Mamm. Rev. 39, 92-123. http://dx.doi.org/10.1111/j.1365-2907.2008.00133.x.

Berland, B., 1961. Nematodes from some Norwegian marine fishies. Sarsia 2, 150.

Bozzano, A., Sardà, F., 2002. Fishery discard consumption rate and scavenging activity in the northwestern Mediterranean Sea. J. Mar. Sci. 59, 15-28.

Burnham, K.P., Anderson, D.R., 1998. Model Selection and Inference: A Practica Information-Theoretical Approach. Springer-Verlag, New York.

Bush, A.O., Lafferty, K.D., Lotz, J.M., Shostak, A.W., 1997. Parasitology meets ecology on its own terms: margolis et al. revisited. J. Parasitol. 83, 575-583.

Carpentieri, P., Colloca, F., Cardinale, M., Belluscio, A., Ardizzone, G.D., 2005. Feeding habits of European hake (Merluccius merluccius) in the central Mediterranean Sea. Fish. Bull. 103, 411-416.

Casey, J., Pereiro, J., 1995. European hake (Merluccius merluccius) in the northeast Atlantic. In: Alheit, J., Pitcher, T.J. (Eds.), Hake: Fisheries, Ecology and Markets. Springer, London, pp. 125-147.

Cimmaruta, R., Bondanelli, P., Nascetti, G., 2005. Genetic structure and environmental heterogeneity in the European hake (Merluccius merluccius). Mol. Ecol. 14, 2577-2591.

Cipriani, P., Smaldone, G., Acerra, V., D'Angelo, L., Anastasio, A., Bellisario, B., Palma, G., Nascetti, G., Mattiucci, S., 2015. Genetic identification and distribution of the parasitic larvae of Anisakis pegreffii and Anisakis simplex (s. s.) in European hake Merluccius merluccius from the Tyrrhenian Sea and Spanish Atlantic coast: implications for food safety. Int. J. Food Microbiol. 198, 1-8.

Cipriani, P., Acerra, V., Bellisario, B., Sbaraglia, G.L., Cheleschi, R., Nascetti, G., Mattiucci, S., 2016. Larval migration of the zoonotic parasite Anisakis pegreffii (Nematoda: anisakidae) in European anchovy, Engraulis encrasicolus: implications to seafood safety. Food Control 59, 148-157.

Cipriani, P., Sbaraglia, G.L., Palomba, M., Giulietti, L., Bellisario, B., Bušelić, I., Mladineo, I., Cheleschi, R., Nascetti, G., Mattiucci, S., 2017. Anisakis pegreffii (Nematoda: Anisakidae) in European anchovy Engraulis encrasicolus, from the Mediterranean Sea: considerations in relation to fishing ground as a driver for parasite distribution. Fish. Res. http://dx.doi.org/10.1016/j.fishres.2017.03.020.

D’Amelio, S., Mathiopoulos, K.D., Brandonisio, O., Lucarelli, G., Doronzo, F., Paggi, L., 1999. Diagnosis of a case of gastric anisakidosis by PCR-based restriction fragment length polymorphism analysis. Parassitologia 41, 591-593.

Darriba, D., Taboada, G.L., Doallo, R., Posada, D., 2012. jModelTest 2: more models, new heuristics and parallel computing. Nat. Methods 9, 772.

Farjallah, S., Slimane, B.B., Busi, M., Paggi, L., Amor, N., Blel, H., Said, K., D’Amelio, S., 2008. Occurrence and molecular identification of Anisakis spp. from the North African coasts of Mediterranean Sea. Parasitol. Res. 102, 371.

Fertl, D., Leatherwood, S., 1997. Cetacean interactions with trawls: a preliminary review. J. Northw. Atl. Fish. Sci. 22, 219-248.

Froese, R., Pauly, D., 2013. Fish Base. http://www.fishbase.org.

Fumarola, L., Monno, R., Ierardi, E., Rizzo, G., Giannelli, G., Lalle, M., et al., 2009. Anisakis pegreffii etiological agent of gastric infections in two Italian women. Foodborne Pathog. Dis. 6, 1157-1159.

Genov, T., Kotnjek, P., Lesjak, J., Hace, A., Fortuna, C.M., 2008. Bottlenose dolphins (Tursiops truncatus) in slovenian and adjacent waters (Northern Adriatic Sea). Ann. Ser. Hist. Nat. 18, 227-244.

González, A.F., Rodríguez, H., Outeirino, L., Vello, C., Larsson, C., Pascual, S., 2017. A Biobanking platform for fish-borne zoonotic parasites: a traceable system to preserve samples, data and money. Fish. Res (in press).

Højgaard, D.P., 1998. Impact of temperature, salinity and light on hatching of eggs of Anisakis simplex (Nematoda, Anisakidae), isolated by a new method, and some remarks on survival of larvae. Sarsia 83, 21-28.

Huelsenbeck, J.P., Ronquist, F., 2005. Bayesian Analysis of Molecular Evolution Using MrBayes. Springer, New York, pp. 183-226.

Inada, T., 1981. Studies on the Merlucciid fishes. Bulletin of the Far Seas. Fish. Res. Lab. $18,172$.

Karl, H., Leinemann, M., 1993. A fast and quantitative detection method for nematodes in fish fillets and fishery products. Arch. Lebensmittelhyg. 44, 124-125.

Karl, H., Levsen, A., 2011. Occurrence and distribution of anisakid nematodes in grey gurnard (Eutrigla gurnardus L.) from the North Sea. Food Control 22, 1634-1638.

Kuhn, T., Cunze, S., Kochmann, J., Klimpel, S., 2016. Environmental variables and definitive host distribution: a habitat suitability modelling for endohelminth parasites in the marine realm. Sci. Rep. 6, 30246.

Levsen, A., Karl, H., 2014. Anisakis simplex (s. 1.) in grey gurnard (Eutrigla gurnardus) from the North Sea: food safety considerations in relation to fishing ground and distribution in the flesh. Food Control 36, 15-19.
Levsen, A., Svanevik, C.S., Cipriani, P., Mattiucci, S., Gay, M., Hastiee, L.C., Pierce, G.J., Bušelić, I., Mladineo, I., Karl, O., Ostermeyer, U., Buchmann, K., Højgaard, D.P., González, A.F., Pascual, S., A survey of zoonotic nematodes of commercial key fish species from major European fishing grounds - introducing the FP7 PARASITE exposure assessment study Fish Res. (accepted paper).

Lim, H., Jung, B.K., Cho, J., Yooyen, T., Shin, E.H., Chai, J.Y., 2015. Molecular diagnosis of cause of anisakiasis in humans, South Korea. Emerg. Infect. Dis. 21, 342-344.

Lundy, C.J., Moran, P., Rico, C., Millner, R.S., Hewitt, G.M., 1999. Macrogeographical population differentiation in oceanic environments: a case study of European hake (Merluccius merluccius), a commercially important fish. Mol. Ecol. 8, 1889-1898.

Mattiucci, S., Nascetti, G., 2006. Molecular systematics, phylogeny and ecology of anisakid nematode of the genus Anisakis Dujardin, 1845: an update. Parasite 13, 99-113.

Mattiucci, S., Nascetti, G., 2008. Advances and trends in the molecular systematics of anisakid nematodes: with implications for their evolutionary ecology and hostparasite co-evolutionary processes. Adv. Parasitol. 66, 47-148.

Mattiucci, S., Paggi, L., Nascetti, G., Abollo, E., Webb, S.C., Pascual, S., Cianchi, R., Bullini, L., 2001. Genetic divergence and reproductive isolation between Anisakis brevispiculata and Anisakis physeteris (Nematoda: Anisakidae). Int. J. Parasitol. 31, 9-14.

Mattiucci, S., Abaunza, P., Ramadori, L., Nascetti, G., 2004. Genetic identification of Anisakis larvae in European hake from Atlantic and Mediterranean waters for stock recognition. J. Fish. Biol. 65, 495-510.

Mattiucci, S., Paoletti, M., Webb, S.C., 2009. Anisakis nascettii n. sp. (Nematoda Anisakidae) from beaked whales of the southern hemisphere: morphological description, genetic relationships between congeners and ecological data. Syst. Parasitol. 74, 199-217.

Mattiucci, S., Paoletti, M., Borrini, F., Palumbo, M., Palmieri, R.M., Gomes, V., Casati, A., Nascetti, G., 2011. First molecular identification of the zoonotic parasite Anisakis pegreffii (Nematoda: anisakidae) in a paraffin-embedded granuloma taken from a case of human intestinal anisakiasis in Italy. BMC Infect. Dis 11, 82.

Mattiucci, S., Fazii, P., De Rosa, A., Paoletti, M., Salomone Megna, A., Glielmo, A., De Angelis, M., Costa, A., Meucci, C., Calvaruso, V., Sorrentini, I., Palma, G., Bruschi, F., Nascetti, G., 2013. Anisakiasis and Gastroallergic reactions associated to Anisakis pegreffii infection. Italy Emerg. Infect. Dis. 19, 496-499.

Mattiucci, S., Cimmaruta, R., Cipriani, P., Abaunza, P., Bellisario, B., Nascetti, G., 2014a. Integrating parasite data and host genetic structure in the frame of an holistic approach for stock identification in Mediterranean Sea fish species. Parasitology 142, 90-108.

Mattiucci, S., Cipriani, P., Webb, S.C., Paoletti, M., Marcer, F., Bellisario, B., Gibson, D.I., Nascetti, G., 2014b. Genetic and morphological approaches distinguish the three sibling species of the Anisakis simplex species complex, with a species designation as Anisakis berlandi n. sp. for A. simplex sp. C (Nematoda: anisakidae). J. Parasitol. 100, 199-214.

Mattiucci, S., Acerra, V., Paoletti, M., Cipriani, P., Levsen, A., Webb, S.C., Canestrelli, D., Nascetti, G., 2016. No more time to stay 'single' in the detection of Anisakis pegreffii, A. simplex (s. s.) and hybridization events between them: a multi-marker nuclear genotyping approach. Parasitol 143, 998-1011.

Mattiucci, S., Cipriani, P., Paoletti, M., Levsen, A., Nascetti, G., 2017a. Reviewing biodiversity and epidemiological aspects of anisakid nematodes from the North East Atlantic Ocean. J. Helmintol. 91, 422-439.

Mattiucci, S., Colantoni, A., Crisafi, B., Mori-Ubaldini, F., Caponi, L., Fazii, P., Nascetti, G., Bruschi, F., 2017b. IgE sensitization to Anisakis pegreffii in Italy: comparison of two methods for the diagnosis of allergic anisakiasis. Parasite Immunol. 39. http:// dx.doi.org/10.1111/pim.12440.

Mellon-Duval, C., De Pontual, H., Métral, L., Quemener, L., 2010. Growth of European hake (Merluccius merluccius) in the Gulf of Lions based on conventional tagging. ICES J. Mar. Sci. 67, 62-70.

Meloni, M., Angelucci, G., Merella, P., Siddi, R., Deiana, C., Orrù, G., Salati, F., 2011. Molecular characterization of Anisakis larvae from fish caught off Sardinia. J. Parasitol. 97, 908-914.

Milano, I., Babbucci, M., Cariani, A., Atanassova, M., Bekkevold Dorte Carvalho, G.R., Espiñeira, M., Fiorentino, F., Garofalo, G., Geffen, A.J., Hansen, J.H., Helyar, S.J., Nielsen, E.E., Ogden, R., Patarnello, T., Stagioni, M., Tinti, F., Bargelloni, L., 2014. Outlier SNP markers reveal fine-scale genetic structuring across European hake populations (Merluccius merluccius). Mol. Ecol. 23, 118-135.

Mladineo, I., Poljak, V., 2014. Ecology and genetic structure of zoonotic Anisakis spp. from Adriatic commercial fish species. Appl. Environ. Microb. 80, 1281-1290.

Mladineo, I., Popović, M., Drmić-Hofman, I., Poljak, V., 2016. A case report of Anisakis pegreffii (Nematoda, Anisakidae) identified from archival paraffin sections of a Croatian patient. BMC Inf. Dis. 16 (42).

Morton, B., Yuen, W.Y., 2000. The feeding behaviour and competition for carrion between two sympatric scavengers on a sandy shore in Hong Kong: the gastropod, Nassarius festivus (Powys) and the hermit crab, Diogenes edwardsii (De Haan). J. Exp. Mar. Biol. Ecol. 246, 1-29.

Oliver, P.A., Massutí, E., 1995. Biology and fisheries of western Mediterranean hake (M. merluccius). In: Alheit, J., Pitcher, T.J. (Eds.), Hake: Biology, Fisheries and Markets. Springer, London, pp. 125-147.

Oro, D., Ruiz, X., 1997. Exploitation of trawler discards by breeding seabirds in the north western Mediterranean: differences between the Ebro Delta and the Balearic Islands areas. ICES J. Mar. Sci. 54, 695-707.

Pekmezci, G.Z., Onuk, E.E., Bolukbas, C.S., Yardimci, B., Gurler, A.T., Acici, M., Umur, S., 2014. Molecular identification of Anisakis species (Nematoda: anisakidae) from marine fishes collected in Turkish waters. Vet. Parasitol. 201, 82-94.

Piras, M.C., Tedde, T., Garippa, G., Virgilio, S., Sanna, D., Farjallah, S., Merella, P., 2014 Molecular and epidemiological data on Anisakis spp. (Nematoda: anisakidae) in commercial fish caught off northern Sardinia (western Mediterranean Sea). Vet. 
Parasitol. 203, 237-240

Posada, D., Buckley, T.R., 2004. Model selection and model averaging in phylogenetics: advantages of Akaike information criterion and Bayesian approaches over likelihood ratio tests. Syst. Biol. 53, 793-808.

Quiazon, K.M., Yoshinaga, T., Ogawa, K., 2011. Experimental challenge of Anisakis simplex sensu stricto and Anisakis pegreffii (Nematoda: anisakidae) in rainbow trout and olive flounder. Parasitol. Int. 60, 126-131.

Reiczigel, J., Rozsa, L., 2005. Quantitative Parasitology 3.0. Budapest. Distributed by the Authors.

Reiczigel, J., 2003. Confidence intervals for the binomial parameter: some new considerations. Stat. Med. 22, 611-621.

Roldan, M.I., Garcia-Marin, J.L., Utter, F.M., Pla, C., 1998. Population genetic structure of European hake, Merluccius merluccius. Heredity 81, 327-334.

Rozsa, L., Reiczigel, J., Majoros, G., 2000. Quantifying parasites in samples of hosts. J. Parasitol. 86, 228-232.

Smrzlić, I.V., Valić, D., Kapetanović, D., Kurtović, B., Teskeredžić, E., 2012. Molecular characterisation of Anisakidae larvae from fish in Adriatic Sea. Parasitol. Res. 111, 2385-2391.

Suzuki, J., Murata, R., Hosaka, M., Araki, J., 2010. Risk factors for human Anisakis infection and association between the geographic origins of Scomber japonicus and anisakid nematodes. Int. J. Food Microbiol. 137, 88-93.

Thompson, J.D., Gibson, T.J., Plewniak, F., Jeanmougin, F., Higgins, D.G., 1997. The CLUSTAL_X windows interface: flexible strategies for multiple sequence alignment aided by quality analysis tools. Nucleic Acid Res. 25, 4876-4882.

Tintore, J., La Violette, P.E., Blade, I., Cruzado, G., 1988. A study of intense density front in the eastern Alboran Sea: the Almeria-Oran front. J. Phys. Oceanogr. 18, 1384-1397.

Umehara, A., Kawakami, Y., Araki, J., Uchida, A., 2007. Molecular identification of the etiological agent of the human anisakiasis in Japan. Parasitol. Int. 56, 211-215.

Valentini, A., Mattiucci, S., Bondanelli, P., Webb, S.C., Mignucci-Giannone, A., ColomLlavina, M.M., Nascetti, G., 2006. Genetic relationships among Anisakis species (Nematoda: anisakidae) inferred from mitochondrial cox2 sequences and comparison with allozyme data. J. Parasitol. 92, 156-166.

Valero, A., Lopez-Cuello, M., Benitez, R., Adroher, F.J., 2006. Anisakis spp. in European hake, Merluccius merluccius (L.) from the Atlantic off north-west Africa and the Mediterranean off southern Spain. Acta Parasitol. 51, 209-212.

Zhu, X.Q., D'Amelio, S., Paggi, L., Gasser, R.B., 2000. Assessing sequence variation in the internal transcribed spacer of ribosomal DNA within and among members of the Contracaecum osculatum complex (Nematoda: ascaridoidea: Anisakidae). Parasitol. Res. 86, 677-683. 